\title{
61
}

\section{Portability as a catalyst for cross-curricular Information Technology permeation}

\author{
Allan Martin \\ University of Glasgow \\ Scotland
}

\begin{abstract}
Genuinely portable computers have relatively recently arrived in secondary schools. The characteristics and usage possibilities enable portables to become effective vehicles for the permeation of information technology (IT) use as a tool for curricular support and enhancement into curricular areas. They may reach educational personnel previously reluctant to adopt IT into their teaching. They may also enable more effective use of IT with girls. The effectiveness is however only fully realized if the portables are used with training and support from IT-literate personnel. An important element in their effectiveness may concern the perception of the computer by teacher and pupil as a cultural object or image.
\end{abstract}

Main conference themes: integration, information technology

Educational areas: secondary education

Study topics:

Secondary keywords: curriculum policies, portable computers 


\section{INFORMATION TECHNOLOGY DISSEMINATION IN SECONDARY SCHOOLS}

Information Technology (IT) is widely seen as having an important role to play in supporting the learning process at all educational levels and in all curricular areas. A recent evaluation of the National Curriculum for England and Wales comments on IT: "Its use is so pervasive that in its basics ... it is a crosscurricular skill which pupils need in education and for later life. These basic skills should therefore become part of the educational core of the National Curriculum" [1]. The fundamental idea underlying National Curriculum IT in England and Wales is that IT is delivered as a set of generalized and transferable skills through the medium of appropriate applications employed to enhance achievement of subject goals across the whole curriculum.

In practice the diffusion of IT across the curriculum in secondary schools in England and Wales has been far from uniform. There has been wide variation, not only between subjects, but also between individual schools. All too often the deciding factor can be the presence or absence of an IT enthusiast in a subject department. In the absence of the resources necessary to carry out the intensive training required to ensure that all teachers make confident and relevant use of IT in the classroom, other strategies must be adopted to encourage and support IT across the whole curriculum.

\section{PORTABLE COMPUTERS AND IT PERMEATION}

Having to use clusters of fixed desktop computers may be an element which dissuades teachers in some subject areas from adopting IT into their programmes. During the 1980s desktop microcomputers gained acceptance as educational tools and many secondary schools are now equipped with one or more computer rooms containing sets of desktop computers, static and usually fixed securely to their desks. To obtain access to computing facilities students must leave their own learning bases and move to the computer room. Computer rooms usually lack the specialized resources as well as the organizational arrangement appropriate to the subject of study. There is an inconvenience factor militating against their use. There is also an image factor in the scientific-technological appearance of both the computer room, often described as a 'laboratory', and the computers themselves which may lead many teachers, particularly in nonscience and nontechnology subjects, who lack IT confidence, to avoid using computers. Finally there may be an ideology factor: teachers in some subject areas may regard technology as alien to the methodology of their subject and dismiss the computer room as irrelevant. 
Using portable computers may reduce the effect of these negative factors. Throughout the 1980s portability was a goal for manufacturers, not for educational reasons, but with saleability to business users in mind. Trends in miniaturization of parts, greater capacity of chips, replacement of metal by plastic elements and the development of liquid crystal display screens made this a feasible goal and before the middle of the decade 'portable' machines were marketed. These were better described as 'luggables' being too heavy as well as bulky to be used other than on a table, and requiring a mains power supply. These machines were also very expensive and enjoyed only limited success. But the early 1990s saw the appearance of genuine 'notebook' computers, light enough to sit on average thighs, compact enough to be used on train or plane, with batteries giving over two hours mains-free usage and with good LCD screens and internal hard disks. The market failure of the luggables stands in direct contrast to the explosive success of genuinely portable computers.

In education the availability of portable computers opens up interesting possibilities. Computers can be taken to the classroom rather than the class being taken to the computer room. The structure of the learning experience set up by the teacher as suitable for subject and class can be maintained with computing facilities inserted in a pedagogically appropriate manner. The small size and moveability of the notebook may also address the image factor in presenting a tool which does not threaten the IT beginner. And by addressing the first two negative factors it may be possible to demonstrate to teachers that students' work in their subject can be enhanced by the use of the computer as a transparent learning tool.

Research in this area is still at an exploratory stage and offering mixed results. Peacock and Breese [2] report little impact on writing tasks and associated language. Gardner and his associates [3, 4] are similarly inconclusive: little improvement in either learning or pupils' attitudes to study in English, mathematics and science could be detected and improvements noted were inconsistent. However, such studies do not always address issues of portability and often focus on the high level of IT access enabled by using portables. Quantitative indicators may also not capture benefits accruing in less tangible areas of activity. Thus, regarding experiences in English lessons, Gardner et al. report that overall learning gains in the areas measured were not significant, but note that "The English teachers were unequivocal in their view that the content and presentation of their pupils' work had been improved. They were also adamant that the quality and effort in the pupils' work was exceptional in comparison to the expectations they would have had for the group under ordinary circumstances" [5]. There is need for further investigation in this area, particularly in relation to the adoption of IT into curricular areas like English where it is less likely to be used. 


\section{PORTABLE COMPUTERS AS A CROSS-CURRICULAR RESOURCE}

The work reported here was carried out between June 1993 and June 1994 by the School of Education of Leeds University and Roundhay School, Leeds, a multi-ethnic urban high school serving the 11-18 age range. Equipment and support came from the Portable Computers in Education Evaluation Project funded by the Department for Education of England and Wales and managed by the National Council for Educational Technology. The aim of the LeedsRoundhay work was to examine:

- How portable computers can enhance teaching and learning across the whole curriculum.

- What role partnerships between teacher educators, teachers and student teachers can play in these processes.

- Particular techniques which exploit the portability of the computer.

- Appropriate management models with such equipment within a school.

These aims shaped the implementation of the project through a series of 'miniprojects' in different curricular areas involving partnership of teachers, university tutors and student teachers in planning, preparation and teaching. The programme is shown in Figure 1. Each miniproject involved up to half a term's activity with one or two classes integrated into the existing curriculum during which time a set of about fifteen A4-size 'notebook' or thirty A5-size 'palmtop' computers would be available. Involvement of the eleven interns (student teachers) placed in the school was a key aspect of the work. In this number were included two majoring in IT.

The initial period (June-September 1993) was one of staff training and familiarization. Staff training was addressed through a mentorship model with novice users linked to an experienced IT user who could offer one-to-one advice and help. The machines were lent over the summer to staff involved in the project and most saw this as a valuable period of preparation. The interns began their course in October; during that term the IT interns provided inservice training for the others.

Activities took place in several subjects. The notebooks were used in English to support a classroom simulation [6], in history to support a time-line exercise, in modern languages to support a survey exercise carried out in French and in technology to aid sixth-form students in the preparation of project work. The palmtops were used in mathematics for work on spreadsheets, in geography to carry out a traffic survey and in physics for datalogging (although hardware and software problems aborted the physics miniproject). 




Fig. 1 Miniproject Programme

\section{RESULTS}

The most immediate and obvious effect of using the portables was upon pupils' motivation. Some comments were:

- "Greatly enhanced their motivation." (teacher, technology)

- "A varied format of lesson inspired a heightened interest level-eagerness for the lesson." (teacher, history) 
- "A dramatic improvement in their motivation without exception. They loved working on the laptops and asked in subsequent lessons whether they could use them again." (intern, modern languages)

- "When we use computers everyone pays attention and tries harder." (pupil, English)

It is noticeable that the motivation factor was present even in those subjects (mathematics and technology) where a fair amount of computer use was already happening. Is there a point at which further use of computers does not have a motivating effect? If so, this evidence would suggest that in most schools there is still a long way to go before that point is reached.

There was less agreement over subject learning gains. In technology the main advantage was seen as convenience because the portables allowed project work to be more easily and effectively carried out. In English gains were identified in knowledge about language, developing arguments, speaking and listening. In modern languages the main gains were seen in convenience and motivation, these two having positive effects on involvement in the work, but gains were also noted in speaking and writing. In history gains were not clear; motivation was seen as important in stimulating greater involvement and the group based activities gave pupils opportunities to discuss historical questions and develop historical argument. In mathematics the use of spreadsheets was a mathematical skill impossible to develop feasibly otherwise and there were clear gains. Skills in mechanical aspects of language were also seen as resulting from using the notebooks with pupils with special educational needs.

There was agreement that useful general skills were practised. Most comments identified experience of particular learning styles as the most important general skills developed, particularly work in pairs or groups, and the increased autonomy of individuals working in selfdirected groups. All observers and participants also agreed that learning gains in IT skills were achieved.

It is important to identify evidence related to the portability of the machines rather than to the sudden insertion of several computers into a classroom. One aspect appreciated by both teachers and pupils was the manoeuvrability of the machines. These could be moved into and out of the classroom, and could thus be temporarily installed, something only achievable with great difficulty with nonportable machines. The fact that the portables could be carried around outside the classroom, came out in the work in technology and geography: "You could use the portable computer near-enough anywhere I wanted to, at home, school and in the common room during free periods." (sixth form pupil, technology). Not only could the portables be moved in and out of the classroom; these could also be disposed within the classroom as the teacher 
wished. This offered teachers flexibility and subordination of the hardware to the learning objectives and organizational requirements of the lesson. This effect was visible to observers and was seen by teachers as a major advantage of using the portables. Difficulties over power supply, sometimes resulting in a profusion of cables and 4-way blocks, were seen as a price worth paying for the benefits gained.

The image of the portable is important. Pupils felt better working with the computers in their own classroom; one girl said she felt 'stressed' working in the computer room, but happy working with computers in the classroom. Pupils also seemed to gain a greater sense of control, because they could move the machines around to a position to suit them. Their small size also made them seem less threatening, less like 'computers' with their air of alien and mechanical intelligence. The size was frequently commented upon and it was noticeable that pupils were able to talk to each other over the machines. It was not always necessary for them to be grouped in front of the computer as is demanded by a nonportable. Pupils could group themselves around the portable in a natural discussion disposition relying on one individual to record the points made; then regroup in an arc to view the product together.

There seemed to be a difference between boys and girls. Pupils in one of the Year 9 (age 13-14) French classes were asked which type of computer they preferred and why; girls tended to prefer laptops as these were easier to use, smaller and neater, while boys tended to prefer desktops due to such features as greater power, better screens and graphics. This difference was reflected in discussion with pupils during other portable-using lessons. It has also been noted in a study of portables in primary classrooms [7]. This might suggest that one benefit to be gained from the use of portable computers is the opportunity afforded to girls to develop as users and controllers of the learning enhancing power of IT.

The project was successful in achieving increased IT activity in several curricular areas with previous IT involvement ranging from high (maths, technology) through medium (modern languages-although largely focused on one teacher, others having very low involvement) to low (English, history, geography). In the high familiarity areas (maths, technology) activities were permitted which would not have been possible on the scale adopted because of competition for the school's existing computer resources. In the medium and low familiarity areas activities were attempted which would previously have been carried out without IT support (English, history) or with more limited IT support based in the computer room (modern languages); teachers and intern teachers who had not previously used IT, were involved.

However, for this cross-curricular penetration to be successful prior training and ongoing support were crucial. The importance of this was 
stressed by teachers and interns. The two IT interns played a major role in supporting the projects; in the classroom they helped set up equipment, introduced the hardware and software to pupils, and taught some of the subject lessons. In all lessons one (occasionally two) of them was available to advise and assist pupils, other interns and teachers. Outside the classroom they provided in-service training to other interns and to some staff. Without their presence it is doubtful if the project would have succeeded; this is not surprising since one of its goals was to take IT to areas where it had penetrated little before and where teachers and interns could be expected to have little or no previous IT experience. In the history project the subject intern and IT intern worked closely together in planning and delivering the lessons. Early training for the English interns enabled them to develop the materials used in the simulation exercise which were provided on disk for pupils. In modern languages the division of expertise in the classroom was clear with IT interns supplying teaching and support in using the computers, while in mathematics both the IT and mathematics intern (who already had some IT familiarity) worked with pupils on both mathematics and IT aspects. Perhaps this reflects the difference between a subject where IT is penetrating well both undergraduate courses and school activities, and those areas where there is still some way to go. It certainly seems that a crucial factor in enabling penetration of IT into low-usage areas is the availability of IT support in the classroom. Advice at the planning stage from an IT literate colleague is also valuable in outlining what hardware and software can do, and in drawing attention to potential problems.

\section{CONCLUSION}

Although this was a case study based in a single school with much of the data collected qualitative rather than quantitative, it nevertheless seems to throw up some ideas and suggestions worthy of discussion and further investigation. Three factors were offered which may affect the take-up of IT in departments where it has previously been little used: inconvenience, image and ideology. This study suggests that the convenience elements attached to portables can support cross-curricular IT dissemination provided their use is accompanied by sufficient training and support from IT literate personnel. Image is also important since reactions to the proposed adoption of IT rest on perceptions and attitudes as well as practical arguments. The image of the computer can attract or deter use; it is seen in the study in connection with gender differences, but image effects may also affect teachers unfamiliar with IT and 
for them the nonthreatening and nontechnological 'selfpresentation' of the portables may be important.

The Leeds-Roundhay work is continuing in order to follow up and focus on some of the questions raised in the first year's work. One of the emphases in this phase will be perceptions of the portable and the desktop computer by staff and pupils. It may then be possible to give more detailed treatment to the questions of image and of professional ideology in relation to portable computers.

\section{REFERENCES}

1. Dearing, R. (1993) The National Curriculum and its Assessment: Interim Report. NCC/SEAC, London, 33.

2. Peacock, M. and Breese, C. (1990) Pupils with Portable Writing Machines. Educational Review, 42, pp. 41-56.

3. Gardner, J., Morrison, H. and Jarman, R. (1993) The Impact of High Access to Computers on Learning. Journal of Computer Assisted Learning, 9, pp. 2-16.

4. Morrison, H., Gardner, J., Reilly, C. and McNally, H. (1993) The Impact of Portable Computers on Pupils' Attitudes to Study. Journal of Computer Assisted Learning, 9, pp. 130-141.

5. Gardner et al., op. cit., 15.

6. Reported in Martin, A. and Clarke, S. (1995) A Language for Europe: some Experience with a Computer-Supported Simulation for the English Classroom, in Simulation and Gaming Yearbook 1995 (ed.) Saunders, D., Kogan Page, London, pp. 274-284.

7. Chatterton, J. and Monteith, M. (1993) Using Portables on Teaching Practice, in Portable Computers in Initial Teacher Education (eds.) Ordidge, I. and France, S., NCET, Coventry, 27. 